\title{
International Preoperative Rectal Cancer Management: Staging, Neoadjuvant Treatment, and Impact of Multidisciplinary Teams
}

\author{
Knut M. Augestad $\cdot$ Rolv-Ole Lindsetmo $\cdot$ Jonah Stulberg $\cdot$ Harry Reynolds $•$ \\ Anthony Senagore - Brad Champagne - Alexander G. Heriot • Fabien Leblanc • \\ Conor P. Delaney • International Rectal Cancer Study Group (IRCSG)
}

Published online: 12 August 2010

(C) The Author(s) 2010. This article is published with open access at Springerlink.com

\begin{abstract}
Background Little is known regarding variations in preoperative treatment and practice for rectal cancer (RC) on an international level, yet practice variation may result in differences in recurrence and survival rates.

Methods One hundred seventy-three international colorectal centers were invited to participate in a survey of preoperative management of rectal cancer.

Results One hundred twenty-three (71\%) responded, with a majority of respondents from North America, Europe, and Asia. Ninety-three percent have more than 5 years' experience with rectal cancer surgery. Fifty-five percent use CT scan, 35\% MRI, 29\% ERUS, 12\% digital rectal examination and $1 \%$ PET scan in all RC cases. Seventyfour percent consider threatened circumferential margin (CRM) an indication for neoadjuvant treatment. Ninety-two
\end{abstract}

Members of the International Rectal Cancer Study Group are listed in Appendix.

K. M. Augestad · R.-O. Lindsetmo · J. Stulberg ·

H. Reynolds · B. Champagne · C. P. Delaney $(\bowtie)$

Division of Colorectal Surgery, University Hospitals Case

Medical Center, 11100 Euclid Avenue, Cleveland,

OH 44106-5047, USA

e-mail: conor.delaney@UHhospitals.org

K. M. Augestad · R.-O. Lindsetmo

Department of Gastrointestinal Surgery, University Hospital

of North Norway, Tromsø, Norway

R.-O. Lindsetmo

Institute of Clinical Medicine, Troms $\varnothing$ University,

Troms $\emptyset$, Norway

K. M. Augestad

Department of Telemedicine and Health Service Research,

University Hospital of North Norway, Troms $\varnothing$, Norway percent prefer 5-FU-based long-course neoadjuvant chemoradiation therapy (CRT). A significant difference in practice exists between the US and non-US surgeons: poor histological differentiation as an indication for CRT $(25 \%$ vs. 7.0\%, $p=0.008)$, CRT for stage II and III rectal cancer (92\% vs. $43 \%, p=0.0001)$, MRI for all RC patients $(20 \%$ vs. $42 \%, p=0.03$ ), and ERUS for all RC patients (43\% vs. $21 \%, p=0.01)$. Multidisciplinary team meetings significantly influence decisions for MRI $(\mathrm{RR}=3.62)$, neoadjuvant treatment (threatened CRM, RR $=5.67$, stage II + III $\mathrm{RR}=2.98)$, quality of pathology report $(\mathrm{RR}=4.85)$, and sphincter-saving surgery $(\mathrm{RR}=3.81)$.

Conclusions There was little consensus on staging, neoadjuvant treatment, and preoperative management of rectal cancer. Regular multidisciplinary team meetings influence decisions about neoadjuvant treatment and staging methods.

\section{J. Stulberg}

Department of Biostatistics and Epidemiology, Case Western Reserve University School of Medicine, Cleveland, OH 44106, USA

A. Senagore

Spectrum Health Care, Department of Surgery, Michigan State University, Grand Rapids, MI 49503, USA

A. G. Heriot

Division of Surgical Oncology, Peter MacCallum Cancer Centre, Melbourne, Australia

F. Leblanc

Department of Digestive Surgery, University Hospitals

of Bordeaux, Bordeaux, France 


\section{Introduction}

A uniform international consensus regarding the optimal management of rectal cancer patients has yet to be developed. Recommendations and guidelines have been published [1-11], but guidelines may lag behind current standards in therapy and it is not known if they are used consistently or universally, even within their respective countries. Differences in practice may influence rectal cancer survival and morbidity. Furthermore, adherence to evidence-based clinical practice in colorectal surgery has been shown to be inconsistent in several reports [12, 13].

Scientific comparison of staging and preoperative treatment of rectal cancer may be hindered by the variety of practice patterns within countries and across international borders. In this context, it is important to evaluate inherent international trends and differences in the management and treatment of rectal cancer. We have conducted a survey regarding current practices of preoperative staging and treatment of rectal cancer among an international panel of colorectal surgeons. The aim of the study was to identify regional differences among international experts that may influence our interpretation of current and future studies regarding the preoperative management of rectal cancer. Furthermore, we wanted to detect the impact of multidisciplinary team meetings and department caseload upon the preoperative decision-making.

\section{Materials and methods}

The study group

A group of six surgeons from the US, Australia, and Europe constituted the working members of an International Rectal Cancer Study Group (IRCSG). All surgeons had more than 10 years of experience with rectal cancer. IRCSG is an independent group without financial support from any companies or organizations and has representatives from Asia, Europe, and North America. The aim of the study group was to evaluate current international treatment practices of rectal cancer.

\section{Invited colorectal surgeons to IRCSG}

Centers and representative surgeons were selected based on prior publications, presentations, or participation at national or international meetings and via a PubMed search for scientific reports on rectal cancer. All respondents were invited to become members of IRCSG. To ensure an experienced international panel, we used two strategies:
1. PubMed search We performed an unsystematic search using the search term rectal cancer combined with staging, treatment, chemotherapy, radiation, surgery. Based upon this search, corresponding authors were identified and included in the survey sample.

2. Oral presentation at an international scientific meeting The working committee of IRCSG participated in several international rectal cancer conferences from 2006 to 2008. Oral presenters in these conferences were identified and included in the survey sample.

The questionnaire

The questionnaire was developed and validated during several meetings of IRCSG. The aim was to cover all aspects of preoperative rectal cancer treatment. Modifications to the survey items were made by literature review and e-mail discussions. The questionnaire consisted of 59 questions. An average of $20 \mathrm{~min}$ was needed to complete the questionnaire.

Study logistics

The survey was sent to the identified colorectal surgeons both as a document attached to an e-mail and as a Web-based survey link forwarded to each participant. The Web-based option was offered through SurveyMonkey. com. Two follow-up e-mails were sent to nonresponders, and the survey was open for a total of 16 weeks.

Review of national guidelines

Six central rectal cancer treatment guidelines were reviewed (Table 1) to compare national recommendations for radiological $\mathrm{T}$ staging and neoadjuvant treatment. The aim was to gain insight in similarities and differences of guideline recommendations.

\section{Statistics}

Descriptive statistics were performed by percentages, $2 \times 2$ contingency tables, and Fisher's exact test. For comparison purposes, respondents were divided into three groups: US-based surgeons, non-US surgeons, and total. Bivariate logistic regression analyses were performed to detect the impact (measured by relative risk [RR]) of department caseload and team meetings upon preoperative decision-making. All tests were two-sided and $p<0.05$ was considered statistically significant. All data were analyzed using SPSS v.16.1 (SPSS, Inc., Chicago, IL). 
Table 1 Guideline recommendations for radiologic T staging and neoadjuvant treatment of rectal cancer [2, 6-8, 10, 11]

\begin{tabular}{|c|c|c|c|c|c|c|}
\hline & $\begin{array}{l}\text { NCCN USA } \\
2009\end{array}$ & $\begin{array}{l}\text { World Congress } \\
2007\end{array}$ & $\begin{array}{l}\text { French } \\
\text { Guidelines } \\
2007\end{array}$ & $\begin{array}{l}\text { Norwegian } \\
\text { Guidelines } 2008\end{array}$ & ESMO 2008 & $\begin{array}{l}\text { Danish } \\
\text { Guidelines } 2009\end{array}$ \\
\hline \multicolumn{7}{|l|}{$\begin{array}{l}\text { Radiological } \\
\text { T staging }\end{array}$} \\
\hline MRI & $\begin{array}{l}\text { Either MRI } \\
\text { or ERUS all } \\
\text { patients }\end{array}$ & $\begin{array}{l}\text { All patients (best to } \\
\text { assess CRM, but } \\
\text { ERUS + CT can } \\
\text { also be used) }\end{array}$ & $\begin{array}{l}\text { All T3-T4 } \\
\text { or N+ after } \\
\text { ERUS }\end{array}$ & All patients & MRI on all T3-T4 & All patients \\
\hline ERUS & $\begin{array}{l}\text { Either MRI } \\
\text { or ERUS all } \\
\text { patients }\end{array}$ & $\begin{array}{l}\text { ERUS + MRI } \\
\text { or ERUS + CT }\end{array}$ & All patients & $\begin{array}{l}\text { ERUS on all early } \\
\text { tumors }(\mathrm{T} 1-\mathrm{T} 2)\end{array}$ & $\begin{array}{l}\text { ERUS on all early } \\
\text { tumors (cT1-T2) }\end{array}$ & $\begin{array}{l}\text { ERUS on all } \\
\text { early tumors }\end{array}$ \\
\hline CT & $\begin{array}{l}\text { CT abdomen/ } \\
\text { thorax all } \\
\text { patients not } \\
\text { recommended } \\
\text { for } \mathrm{T} \text { staging }\end{array}$ & $\begin{array}{l}\text { CT abdomen/thorax } \\
\text { all patients }\end{array}$ & $\begin{array}{l}\text { CT thorax/ } \\
\text { abdomen all } \\
\text { patients }\end{array}$ & $\begin{array}{l}\text { CT pelvis is an } \\
\text { alternative to } \\
\text { MRI when no } \\
\text { access to MRI }\end{array}$ & $\begin{array}{l}\text { CT abdomen/thorax all } \\
\text { patients (alternatively } \\
\text { chest X-ray and } \\
\text { ultrasound of liver) }\end{array}$ & $\begin{array}{l}\text { CT thorax/ } \\
\text { abdomen all } \\
\text { patients }\end{array}$ \\
\hline PET scan & $\begin{array}{l}\text { Not routinely } \\
\text { indicated }\end{array}$ & $\begin{array}{l}\text { Indicated only when } \\
\text { lesions in liver }\end{array}$ & $\begin{array}{l}\text { Not routinely } \\
\text { indicated }\end{array}$ & NA & NA & $\begin{array}{l}\text { Only indicated } \\
\text { when suspicion } \\
\text { of extrahepatic } \\
\text { metastasis }\end{array}$ \\
\hline \multicolumn{7}{|l|}{$\begin{array}{l}\text { Neoadjuvant } \\
\text { treatment }\end{array}$} \\
\hline T1-2, N0 & $\begin{array}{l}\text { No neoadjuvant } \\
\text { treatment }\end{array}$ & RCT T2 & $\begin{array}{l}\text { No neoadjuvant } \\
\text { treatment }\end{array}$ & $\begin{array}{l}\text { No neoadjuvant } \\
\text { treatment }\end{array}$ & $\begin{array}{l}\text { No neoadjuvant } \\
\text { treatment }\end{array}$ & $\begin{array}{l}\text { No neoadjuvant } \\
\text { treatment }\end{array}$ \\
\hline $\begin{array}{l}\text { T3, N0 or T } \\
\text { any, N1-2 } \\
\text { (stage II or } \\
\text { III) }\end{array}$ & $\mathrm{RCT}$ & $\begin{array}{l}\text { Radiation alone } \\
\text { or RCT }\end{array}$ & $\begin{array}{l}\text { Radiation alone } \\
\text { or RCT (no } \\
\text { treatment to } \\
\text { T3N0 with } \\
\text { CRM }>1 \mathrm{~mm} \text { ) }\end{array}$ & See CRM & $\begin{array}{l}\text { No RCT early T3. } \\
\text { Radiation alone } \\
\text { or RCT }\end{array}$ & $\begin{array}{l}\text { RCT midrectal } \\
\text { T3 with CRM } \\
<5 \mathrm{~mm} \text {. All } \\
\text { low rectal T3 }\end{array}$ \\
\hline $\mathrm{T} 4$ & $\mathrm{RCT}$ & RCT & $\begin{array}{l}\text { Radiation alone } \\
\text { or RCT }\end{array}$ & RCT & $\mathrm{RCT}$ & $\begin{array}{l}\text { RCT to mid and } \\
\text { low } \mathrm{T} 4\end{array}$ \\
\hline CRM & NA & NA & $\begin{array}{l}\text { Radiation or } \\
\text { RCT when } \\
\text { CRM }<1 \mathrm{~mm}\end{array}$ & $\begin{array}{l}\mathrm{CRM}<3 \mathrm{~mm} \\
\mathrm{RCT}\end{array}$ & NA & See T3 \\
\hline
\end{tabular}

NCCN National Comprehensive Cancer Network, ERUS endoscopic rectal ultrasound, CRM circumferential margin, NA no information, $R C T$ chemoradiotherapy

\section{Results}

One hundred seventy-three colorectal surgeons were identified and contacted via e-mail. After one initial e-mail and two follow-up e-mails, $123(71 \%)$ surgeons responded. One hundred one responded via the Web-based questionnaire, 20 by returning the questionnaire as an e-mail attachment, and 2 by fax. Of those that returned the survey, $110(89 \%)$ fully completed all parts of the questionnaire.

\section{Demographics (Table 2)}

The colorectal centers were located in 28 countries representing five continents: 53 in North America, 43 in Europe, 18 in Asia, 8 in South America, and 1 in Africa. Seventyeight percent were university hospitals.
Rectal surgery experience (Table 2)

Ninety-three percent of responding surgeons have more than 5 years' experience with rectal cancer surgery, and $70 \%$ work in departments that manage more than 50 rectal cancers per year. Twenty percent of the surgeons perform more than 50 rectal cancer operations annually.

Preoperative staging (Table 3)

Fifty-five percent of surgeons prefer CT scan, 35\% MRI, $29 \%$ rectal ultrasound, $12 \%$ digital rectal examination, and $1 \%$ PET scan in all rectal cancer patients for preoperative staging. All use more than one imaging modality in all rectal cancer patients for preoperative staging. Significantly more non-US surgeons use MRI on all rectal cancer 
Table 2 Hospital affiliation, department caseload, and rectal cancer surgical experience $(n=123)$

\begin{tabular}{|c|c|c|c|}
\hline & US $[n(\%)]$ & Non-US $[n(\%)]$ & Total $[n(\%)]$ \\
\hline \multicolumn{4}{|c|}{ Hospital location } \\
\hline City & $1(2.3)$ & $11(13.9)$ & $12(9.8)$ \\
\hline Rural & $1(2.3)$ & 0 & $1(0.8)$ \\
\hline Private & 7 (15.9) & $7(8.8)$ & $14(11.4)$ \\
\hline University & $35(79.5)$ & $61(77.2)$ & $96(78.0)$ \\
\hline \multicolumn{4}{|l|}{ Experience } \\
\hline$<5$ years & $4(9.1)$ & $4(5.0)$ & $8(6.5)$ \\
\hline $5-10$ years & $12(27.3)$ & $17(21.5)$ & $29(23.6)$ \\
\hline $11-20$ years & $16(36.4)$ & $27(34.1)$ & $43(35.0)$ \\
\hline$>20$ years & $12(27.3)$ & $31(39.2)$ & $43(35.0)$ \\
\hline \multicolumn{4}{|c|}{$R C$ surgeries/year } \\
\hline$<10$ & $2(4.5)$ & $3(3.7)$ & $5(4.1)$ \\
\hline $10-20$ & $10(22.7)$ & $18(22.7)$ & $28(22.8)$ \\
\hline $21-30$ & $10(22.7)$ & $24(30.3)$ & $34(27.6)$ \\
\hline $31-50$ & $14(31.8)$ & $18(22.7)$ & $32(26.0)$ \\
\hline$>50$ & $8(18.2)$ & $16(20.2)$ & $24(19.5)$ \\
\hline \multicolumn{4}{|c|}{ Hospital caseload } \\
\hline$<10$ & 0 & $2(2.5)$ & $2(1.6)$ \\
\hline $11-30$ & $4(9.1)$ & $4(5.0)$ & $8(6.5)$ \\
\hline $31-50$ & $11(25.0)$ & $16(20.2)$ & $27(22.0)$ \\
\hline $51-70$ & 7 (15.9) & $13(16.4)$ & $20(16.3)$ \\
\hline $71-90$ & $11(25.0)$ & $21(26.5)$ & $32(26.0)$ \\
\hline$>90$ & $11(25.0)$ & $23(29.1)$ & $34(27.6)$ \\
\hline
\end{tabular}

Experience Respondents experience with rectal cancer surgery, $R C$ surgeries/year Respondents caseload of rectal cancer surgery, Hospital caseload Number of rectal cancer surgeries performed at the department each year

patients compared to US surgeons (42\% vs. $20 \%$, $p=0.03)$. US surgeons prefer ERUS significantly more than non-US surgeons do ( $43 \%$ vs. $21 \%, p=0.01)$. Similarly, we detected a difference in PET scan use: $53 \%$ of non-US surgeons and $25 \%$ of US surgeons never use PET $\operatorname{scan}(p=0.005)$.

\section{Indications for preoperative chemoradiotherapy (CRT)} (Table 4)

Eighty-one surgeons (73\%) consider threatened circumferential margin (CRM) an indication for neoadjuvant treatment. Of those, $40 \%$ consider $1 \mathrm{~mm}$ or less, $39 \%$ consider $2 \mathrm{~mm}$ or less, and $21 \%$ consider $3 \mathrm{~mm}$ or less as threatened CRM. Sixty-seven (61\%) always give neoadjuvant treatment to both stage II and stage III rectal cancer patients. However, two US surgeons and two non-US surgeons answered "others" for "give preoperative CRT treatment to all T3 cancers and greater," which means stage II or higher.

Ninety-two percent of US surgeons compared to $43 \%$ non-US surgeons give CRT for stage II and stage III rectal cancers ( $p=0.0001)$. A significantly higher proportion of US surgeons consider rectal cancer with poor histological differentiation an indication for CRT (10/39 vs. 5/71, $p=0.008)$. Cancer in the distal third of the rectum is an indication for preoperative CRT for 15 (14\%) surgeons, while cancer in the distal two-thirds is used by five $(5 \%)$ surgeons, and one (1\%) gives neoadjuvant treatment to all rectal cancer patients.

Neoadjuvant treatment and other preoperative considerations (Table 5)

Ninety-two percent prefer 5-fluorouracil (5-FU)-based long-course neoadjuvant CRT. Ten percent (4) of the US surgeons and $16 \%$ (12) of non-US surgeons prefer short-course radiation therapy. A significantly higher proportion of the US surgeons have radiation therapy available at their hospital ( $89 \%$ vs. $74 \%, p=0.04)$, and significantly more of non-US surgeons have regular rectal cancer audits (74\% vs. $51 \%, p=0.01)$.

Institutional radiation rate (Fig. 1)

Twenty-nine of 39 US surgeons have an institutional irradiation rate (IRR) $>50 \%$ and $31 / 71$ non-US surgeons have an IRR $>50 \%(p=0.001)$. However, nine ( $8 \%)$ surgeons answered that their institution offers radiation to more than $90 \%$ of all rectal cancer patients, and a similar proportion (8\%) have an IRR of $10-29 \%$.

Impact of multidisciplinary teams and caseload (Table 6)

Departments with regular multidisciplinary team meetings are more likely to prefer MRI for local staging $(\mathrm{RR}=3.62)$, and there is a trend toward significance $(p=0.06)$. Similarly, patients with threatened circumferential margin are more likely to receive neoadjuvant treatment in departments with team meetings $(\mathrm{RR}=5.67, p=0.03)$. Other significant impacts of team meetings were found upon pathology report quality $(\mathrm{RR}=4.85, p=0.01)$, new chemotherapy regimen if there are liver metastases $(\mathrm{RR}=6.41, p=0.02)$, and one-stage surgery when there are liver metastases $(\mathrm{RR}=0.25, p=0.02)$. Similar influences of caseload upon preoperative decision-making were not observed.

\section{Discussion}

This is the first survey of current practice among international colorectal centers regarding preoperative management of rectal cancer. The results demonstrate a wide variation 
Table 3 Preference of image modality for staging of rectal cancer
Question: Which of the following procedures for rectal cancer staging do you use in your daily practice? (Please choose an answer for each method)

All of the responding surgeons use more than one imaging modality in all rectal cancer patients

MRI magnetic resonance imaging, ERUS endoscopic rectal ultrasound,

$C T$ computerized tomography, PET scan positron emission tomography, DRE under GA digital rectal examination under general anesthesia, $N S$ not significant

\begin{tabular}{|c|c|c|c|c|}
\hline & US $[n(\%)]$ & Non-US [ $n(\%)]$ & Total $[n(\%)]$ & $p$ value \\
\hline \multicolumn{5}{|l|}{ MRI } \\
\hline Never & 7 (17.9) & $5(5.0)$ & 13 (11.8) & NS \\
\hline Selected & $24(61.5)$ & $35(49.2)$ & $59(53.6)$ & NS \\
\hline All & $8(20.5)$ & $30(42.2)$ & $38(34.5)$ & 0.03 \\
\hline \multicolumn{5}{|l|}{ ERUS } \\
\hline Never & $2(5.1)$ & $10(14.0)$ & $12(10.9)$ & NS \\
\hline Selected & $20(51.3)$ & $46(64.7)$ & $66(60.0)$ & NS \\
\hline All & 17 (43.6) & $15(21.1)$ & $32(29.1)$ & 0.01 \\
\hline \multicolumn{5}{|l|}{$\mathrm{CT}$} \\
\hline Never & $6(15,4)$ & $13(18.3)$ & $19(17.3)$ & NS \\
\hline Selected & $11(28,2)$ & $20(28.1)$ & $31(28.2)$ & NS \\
\hline All & $22(56,4)$ & $38(53.5)$ & $60(54.5)$ & NS \\
\hline \multicolumn{5}{|l|}{ PET scan } \\
\hline Never & $10(25.6)$ & $38(53.5)$ & $48(43.6)$ & 0.005 \\
\hline Selected & $28(71,8)$ & $33(46.4)$ & $61(55.5)$ & 0.01 \\
\hline All & $1(2.6)$ & $0(0.0)$ & $1(0.9)$ & NS \\
\hline \multicolumn{5}{|l|}{ DRE under GA } \\
\hline Never & $20(51.3)$ & $43(60.5)$ & $63(57.3)$ & NS \\
\hline Selected & $16(41.0)$ & $18(25.3)$ & $34(30.9)$ & NS \\
\hline All & $3(7.7)$ & $10(14.0)$ & $13(11.8)$ & NS \\
\hline Total (missing) & $39(5)$ & $71(8)$ & $110(13)$ & \\
\hline
\end{tabular}

in preoperative staging procedures, inconsistencies in indications for preoperative CRT, and differences in treatment procedures for identical rectal cancers. These variations highlight the need for more and better scientific evidence to help guide rectal cancer treatment as well as the need for international focus upon development of guidelines.

There exist several guidelines for rectal cancer treatment, at both national and international levels. New guidelines have recently been published [9]. However, these guidelines vary in their recommendations (Table 1). Similarly, practice may vary between countries and continents because surgeons prefer treatment according to their own guidelines. Implementation of national guidelines of clinical practice seems slow, as pointed out in other surveys [12, 13] and has been demonstrated among colorectal surgeons [14-18]. The differences in preoperative staging and treatment options cannot be explained by the heterogeneity of the institutional affiliations of the participants. As the vast majority of the responding colorectal surgeons work in academic medical centers, the differences in current practices reflect the lack of clinical evidence or the slow implementation of such evidence. Evidence from the US about adherence to preoperative staging and treatment options suggests marked variation. For the eight centers that participate in the National Comprehensive Cancer Network (NCCN), adherence to guidelines and quality measures is variable [18]. Concordance with guidelines is recently discussed in an editorial by Browman [19].
Certainly, it is important to indicate how well a recommendation is aligned with the evidence from which it is derived, but it is uncertain how practitioners interpret, respond to, or act upon a recommendation. We think our study reflects this argument, showing inconsistent practice also within continents and national borders.

Variations in preoperative staging imaging will select identical rectal cancer patients to undergo different treatment regimens depending on the sensitivity and specificity of the selected imaging modality. MRI and rectal ultrasound have better diagnostic properties than CT for rectal cancer [20, 21], but still CT is used for local staging by $54.5 \%$ of the surgeons compared to $34.5 \%$ that prefer MRI for all rectal cancer patients. The distance to the CRM has been increasingly recognized as an important factor and a surrogate marker for local recurrence. In this context, MRI has increased in popularity because of its ability to help decide the distance to the CRM and it should be used widely for preoperative treatment planning. CT has little or no place in describing the distance to the CRM because of its low spatial resolution. A recently published review recommends the use of MRI for all rectal cancer patients [22]. In our study, $11 \%$ of respondents never use MRI and approximately $50 \%$ use it in selected cases. In our opinion these numbers are surprisingly low and might reflect the slow implementation of evidence-based medicine among colorectal surgeons. All centers in this study use more than one staging procedure. $\mathrm{CT}$ has a role in evaluating the 
Table 4 Indications for preoperative chemoradiotherapy

\begin{tabular}{|c|c|c|c|c|}
\hline & US $[n(\%)]$ & Non-US $[n(\%)]$ & Total $[n(\%)]$ & $p$ value \\
\hline All RC & 0 & 1 & $1(0.9)$ & NS \\
\hline Stage II and III RC & $36(92.3)$ & $31(43.6)$ & $67(60.9)$ & 0.001 \\
\hline $\mathrm{CRM} \leq 1 \mathrm{~mm}^{\mathrm{a}}$ & $13(33.3)$ & $27(38.0)$ & $40(36.4)$ & NS \\
\hline $\mathrm{CRM} \leq 2 \mathrm{~mm}^{\mathrm{a}}$ & $10(25.6)$ & $28(39.4)$ & $38(34.5)$ & NS \\
\hline $\mathrm{CRM} \leq 3 \mathrm{~mm}^{\mathrm{a}}$ & $4(10.3)$ & $17(23.9)$ & $21(19.1)$ & NS \\
\hline Mesorectal growth $\geq 5 \mathrm{~mm}^{\mathrm{a}}$ & $5(12.8)$ & $16(22.5)$ & $21(19.1)$ & NS \\
\hline Mesorectal growth $\geq 5 \mathrm{~mm} \leq 15 \mathrm{~mm}^{\mathrm{a}}$ & $2(5.1)$ & $5(7.0)$ & $7(6.4)$ & NS \\
\hline Any $\mathrm{RC}$ in distal third of rectum & $4(10.3)$ & $11(15.4)$ & $15(13.6)$ & NS \\
\hline Any $\mathrm{RC}$ in distal two-thirds of rectum & $3(7.7)$ & $2(2.8)$ & $5(4.5)$ & NS \\
\hline Any $\mathrm{RC}$ with poor differentiation & $10(25.6)$ & $5(7.0)$ & $15(13.6)$ & 0.008 \\
\hline Total (missing) & $39(5)$ & $71(8)$ & $110(13)$ & \\
\hline
\end{tabular}

$C R M$ circumferential margin, $C R T$ chemoradiotherapy, $R C$ rectal cancer

${ }^{a}$ Assessed by MRI, ERUS (endoscopic rectal ultrasound), or CT

Question: Which indications do you follow as indications for neoadjuvant treatment? (Please choose all that apply to you)

Indications for neoadjuvant treatment other than those listed: 1 . Age of patient. 2. Nodal status, vascular invasion status. 3. Local fixity/invasion of adjacent organ on CT. 4. Any margins at risk, multiple nodes, and/or deep extension into mesorectum. 5. No CRT for proximal stage II rectal cancers. 6. N2 on MRI. 7. Selected stage I disease before local excision—part of a national trial. 8. Stage II or III in the lower 1/3 rectal cancer. 9. Anterior tumor, distal 1/3 rectum in a male patient. 10. Stage III in the lower third and infiltration of the sphincter. 11. Stage II or III low rectal cancers and T4 cancer any level.12. MRI threatened margin, long-course CRT. For those with clear margin, short-course CRT. Any nodal disease, long-course CRT. 13. Preoperative staged higher than T3N1. 14. Distal third, not cT1 (all cT3 or cN+ or cT2 in lower third). 15. Presumed positive lymph node on MRI. 16. Bulky tumor. 17. More than four suspected LN (N2). 18. T3-T4, any suggestions of LN involvement. 19. Fixed rectal cancers or rectal cancers with large lymph nodes only. 20 . T3 cancers, T2 cancers with enlarged nodes, tumors below the peritoneal reflection. 21. T3 male mid, lower rectal cancer, T4 female mid, lower rectal cancer. 22. Proportionally big tumors for the pelvis. 25. Histology: lymphovascular invasion. 26. Any cT3 - or cN+ rectal cancer of the distal third; any ultralow T1/T2 cancer when sphincter preservation is a goal; bulky tumors of distal and middle third in male patients. 27. Lower threshold for CRT in lower third. 28. Fixed rectal cancers or rectal cancers with large lymph nodes only. 29. Sphincter involvement. 30. Anterior locations in males. 31. All N+. 32. Nodal involvement on preoperative imaging. 33. Large T3 and all T4 tumors (long course) and some borderline T2/T3 tumors (short course) independent of preop nodal status. 34. T4 cancers, multiple large lymph nodes, iv growth. 35. Candidates for APR and severe tumor fixation by digital rectal examination. 36. Anterior tumor. 37. Stage III rectal cancer, before Miles operation. 38. Locally advanced and stage III rectal cancers. 39. T4 cancer below the peritoneal reflection. 40. Enlarged nodes on imaging; T3 or greater; close enough to anorectal ring that shrinkage with neoadjuvant therapy may improve chance of sphincter-sparing surgery in patient with good performance status. 41. uT3, uT4, $\mathrm{uN}+$. 42. Big tumors at the lower third of the rectum, especially in males. 43. But not all small posterior T3N0. 44. Positive mesorectal nodes on imaging

infiltration of other organs, usually for large T4 tumors. In addition, CT is used to determine metastatic disease in the liver and/or lungs ( $M$ stage in the TNM classification). Endoscopic rectal ultrasound (ERUS) has a role in evaluating small tumors for which local excision might be feasible. Retrospectively, it might be argued that some surgeons participating in the survey answered the question with respect to $M$ staging and that this might bias the results regarding CT use (54\% use it on all patients). However, the questionnaire specifically says "CT scan of the pelvis," i.e., local staging, which reflects the actual use of CT for local staging (either alone or in combination with other modalities). In contrast, we do believe that CT is the most common modality for $\mathrm{M}$ staging.

Generalization of the results from this study must be made with care. The invited surgeons were selected based upon publications listed in PubMed and presentation or participation at national or international meetings, thus respondents could be prone to selection bias. However, the respondents were from large university hospitals throughout the world $(78 \%)$ as well as from other large hospitals with a relatively high volume of rectal cancer patients, and the participants are all published authors and teachers at national meetings. Similarly, the surgical experience among the respondents is high: 93\% of the responding surgeons have experience with rectal cancer treatment for more than 5 years, and $35 \%$ have experience for more than 20 years (Table 2). Thus, in our opinion the respondents are thoroughly experienced and good representatives for their national rectal cancer practice.

This survey has revealed prominent variations in practice standards in the preoperative staging and treatment of rectal cancer. The survey emphasizes the need for establishing an international consensus for the management of patients with rectal cancer and for identifying areas for future research. An international consensus is needed in order to develop staging and preoperative treatment standards if outcomes are to be compared 
Table 5 Neoadjuvant treatment and preoperative considerations

\begin{tabular}{|c|c|c|c|c|}
\hline & $\begin{array}{l}\mathrm{US} \\
{[n(\%)]}\end{array}$ & $\begin{array}{l}\text { Non-US } \\
{[n(\%)]}\end{array}$ & $\begin{array}{l}\text { Total } \\
{[n(\%)]}\end{array}$ & $p$ value \\
\hline Threatened CRM as an indication for neoadjuvant therapy & $26(66.7)$ & $55(77.4)$ & $81(73.6)$ & NS \\
\hline Short-course radiation therapy $(5 \mathrm{~Gy} \times 5)^{\mathrm{a}}$ & $4(10.3)$ & $12(16.9)$ & $16(14.5)$ & NS \\
\hline Long-term chemoradiation regimen $(1.8-2 \mathrm{~Gy} \times 25)^{\mathrm{a}}$ & $37(94.9)$ & $64(90.1)$ & $101(91.87)$ & NS \\
\hline Other neoadjuvant therapy & $2(5.1)$ & $11(15.4)$ & $13(11.8)$ & NS \\
\hline Radiation therapy available & $35(89.7)$ & $53(74.6)$ & $88(80.0)$ & 0.04 \\
\hline Intraoperative radiation therapy available & $11(28.2)$ & $14(19.7)$ & $25(22.7)$ & NS \\
\hline $\begin{array}{l}\text { Internal sphincter-saving surgery in case of complete tumor response after neoadjuvant } \\
\text { therapy }\end{array}$ & $22(56.4)$ & $34(47.8)$ & $56(50.9)$ & NS \\
\hline $\begin{array}{l}\text { External sphincter-saving surgery in case of complete tumor response after neoadjuvant } \\
\text { treatment }\end{array}$ & $5(12.8)$ & $11(15.4)$ & $16(14,5)$ & NS \\
\hline Alternation of neoadjuvant treatment if synchronous liver metastasis & $20(51.3)$ & $28(39.4)$ & $48(43.6)$ & NS \\
\hline Treatment plans within an interdisciplinary team & $37(94.9)$ & $60(84.5)$ & $97(86,6)$ & NS \\
\hline Only specialized centers & $33(84.6)$ & $60(84.5)$ & $93(83)$ & NS \\
\hline Abdominoperineal resection is a surrogate marker for the quality of RC surgery & $15(38.5)$ & $39(54.9)$ & $54(48.2)$ & NS \\
\hline Weekly/monthly RC audits & $20(51.3)$ & $53(74.6)$ & $73(65.2)$ & 0.01 \\
\hline Total (missing) & $39(5)$ & $71(8)$ & $110(13)$ & \\
\hline
\end{tabular}

CRM circumferential margin

${ }^{a}$ Thirteen (11.8\%) surgeons report different practice than short- or long-course CRT, i.e., 8 oxaliplatin-based CRT, 1 long-term chemoradiation but wait 8-10 weeks, 1 short-term radiation with delayed surgery (5-7 weeks), 1 both regimens depending on MRI findings, 1 no radiation

Fig. 1 Institutional irradiation rate (IRR) for rectal cancer at 123 international centers. Significantly more US centers (29/39) have IRR $>50 \%$ compared to non-US centers $(31 / 71)(p=0.001)$

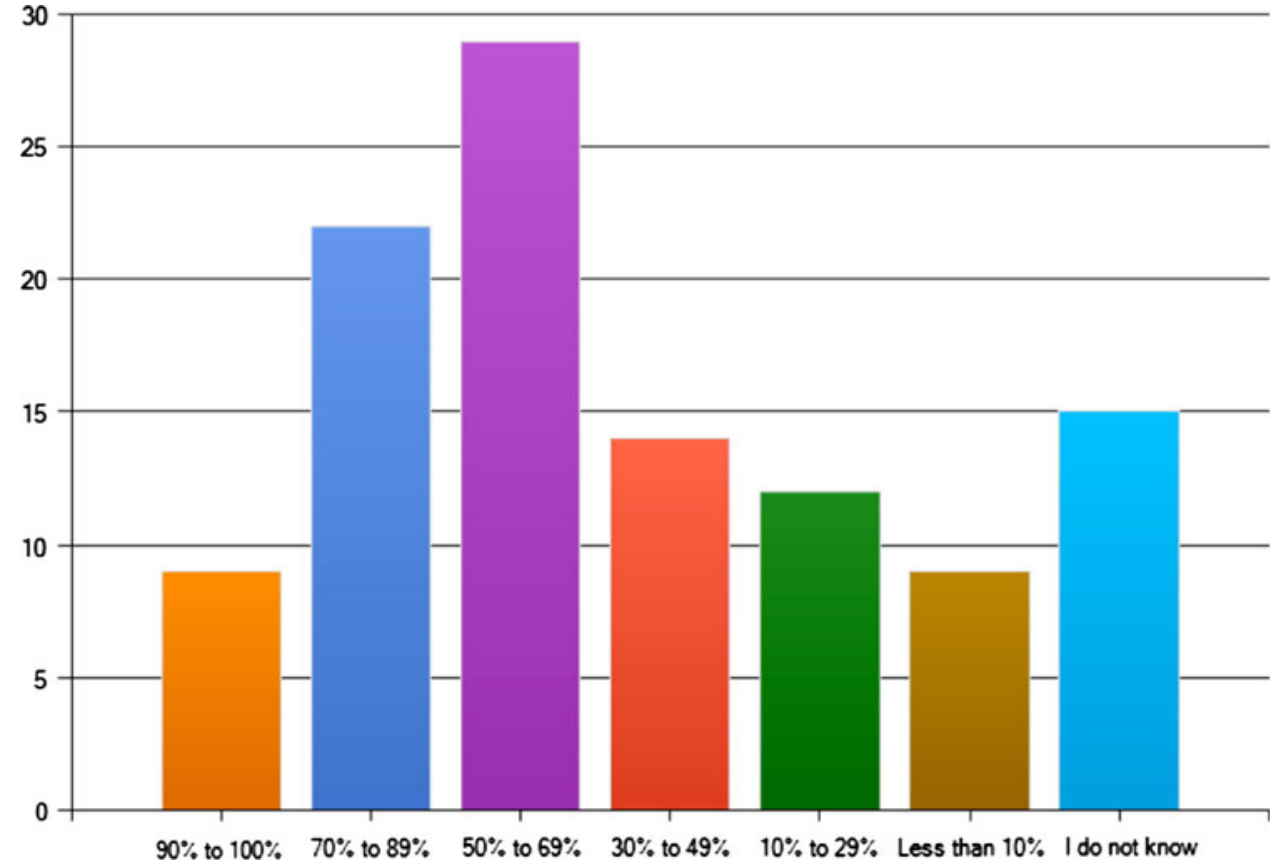

between institutions and countries. Focusing on standardization and documentation as a process may also improve results [23]. The survey also points out the need for agreement on the staging and neoadjuvant treatment modalities used if we are to compare outcomes in rectal cancer treatment.

The different indications for neoadjuvant treatment will select noncomparable groups of patients in outcome studies. Different staging procedures and treatment algorithms could certainly reflect the published differences in local recurrence rates and 5-year cancer-specific survival rates [24, 25]. Heald [26] standardized the surgical technique for rectal cancer surgery with a significant impact on the risk of local recurrence. Probably an evidence-based standardization of preoperative practices will also benefit rectal cancer patients [27]. 
Table 6 Impact of caseload and multidisciplinary teams upon preoperative descision-making

\begin{tabular}{|c|c|c|c|c|c|}
\hline & & \multirow[t]{2}{*}{ Relative risk } & \multirow[t]{2}{*}{$p$} & \multicolumn{2}{|c|}{$95 \%$ confidence interval } \\
\hline & & & & Lower bound & Higher bound \\
\hline \multicolumn{6}{|l|}{ Staging method } \\
\hline \multirow[t]{2}{*}{ MRI } & Cload & 1.33 & 0.21 & 0.82 & 2.15 \\
\hline & Team & 3.62 & 0.06 & 0.93 & 14.03 \\
\hline \multirow[t]{2}{*}{ ERUS } & Cload & 0.89 & 0.80 & 0.54 & 1.47 \\
\hline & Team & 3.12 & 0.23 & 0.65 & 15.03 \\
\hline \multirow[t]{2}{*}{ PET } & Cload & 1.24 & 0.11 & 0.93 & 1.66 \\
\hline & Team & 2.27 & 0.16 & 0.73 & 7.07 \\
\hline \multirow[t]{2}{*}{ CT Pelvis } & Cload & 1.30 & 0.14 & 0.96 & 2.06 \\
\hline & Team & 0.67 & 0.62 & 0.27 & 6.78 \\
\hline \multirow[t]{2}{*}{ DRE } & Cload & 1.15 & 0.27 & 0.86 & 1.52 \\
\hline & Team & 1.17 & 0.79 & 0.38 & 3.61 \\
\hline \multicolumn{6}{|c|}{ Indication for neoadjuvant treatment } \\
\hline \multirow[t]{2}{*}{ Stg II + III } & Cload & 1.24 & 0.07 & 0.91 & 1.68 \\
\hline & Team & 2.98 & 0.08 & 0.91 & 9.74 \\
\hline \multirow[t]{2}{*}{ CRM } & Cload & 1.06 & 0.69 & 0.73 & 1.33 \\
\hline & Team & 5.67 & 0.003 & 1.80 & 17.89 \\
\hline \multirow[t]{2}{*}{ Mesorectal $<5 \mathrm{~mm}$} & Cload & 1.09 & 0.60 & 0.77 & 1.55 \\
\hline & Team & 1.60 & 0.55 & 0.33 & 7.73 \\
\hline \multirow[t]{2}{*}{ Mesorectal 5-15 mm } & Cload & 0.99 & 0.99 & 0.55 & 1.78 \\
\hline & Team & $<0.01$ & 0.99 & $<0.01$ & $<0.01$ \\
\hline \multirow[t]{2}{*}{ Distal $1 / 3$} & Cload & 0.97 & 0.91 & 0.64 & 1.48 \\
\hline & Team & $<0.01$ & 0.91 & $<0.01$ & $<0.01$ \\
\hline \multirow[t]{2}{*}{ Distal 2/3 } & Cload & 1.84 & 0.09 & 0.90 & 3.76 \\
\hline & Team & $<0.01$ & 0.99 & $<0.01$ & $<0.01$ \\
\hline \multirow[t]{2}{*}{ Poor differentiation } & Cload & 0.74 & 0.14 & 0.50 & 1.10 \\
\hline & Team & 1.71 & 0.45 & 0.41 & 7.14 \\
\hline \multicolumn{6}{|c|}{ Other preoperative preferences } \\
\hline \multirow[t]{2}{*}{ Pathology report } & Cload & 1.17 & 0.45 & 0.77 & 1.76 \\
\hline & Team & 4.85 & 0.01 & 1.34 & 17.46 \\
\hline \multirow[t]{2}{*}{ IORT } & Cload & 1.36 & 0.11 & 0.94 & 1.97 \\
\hline & Team & $<0.01$ & 0.99 & $<0.01$ & $<0.01$ \\
\hline \multirow[t]{2}{*}{ SSS initial imaging } & Cload & 1.00 & 0.88 & 0.76 & 1.34 \\
\hline & Team & 3.81 & 0.09 & 0.98 & 14.72 \\
\hline \multirow[t]{2}{*}{ New regimen liver met } & Cload & 1.38 & 0.03 & 0.52 & 0.97 \\
\hline & Team & 6.41 & 0.02 & 1.34 & 30.64 \\
\hline \multirow[t]{2}{*}{ One-stage surgery } & Cload & 1.23 & 0.17 & 0.91 & 1.64 \\
\hline & Team & 0.25 & 0.02 & 0.08 & 0.80 \\
\hline \multirow[t]{2}{*}{ APR rate $<10 \%$} & Cload & 1.00 & 0.91 & 0.72 & 1.39 \\
\hline & Team & 1.05 & 0.87 & 0.31 & 3.90 \\
\hline \multirow[t]{2}{*}{ IRR $>50 \%$} & Cload & 0.91 & 0.59 & 0.66 & 1.26 \\
\hline & Team & 0.22 & 0.01 & 0.62 & 0.78 \\
\hline
\end{tabular}

Cload caseload, divided into 6 groups, see Table 1, Team = regular multidisciplinary team meetings to plan rectal cancer treatment, MRI magnetic resonance imaging, ERUS = endoscopic rectal ultrasound, PET PET scan, DRE digital rectal exam under anesthesia, Stg II + III stage II and III rectal cancer, $C R M$ use of the preoperatively assessed circumferential margin (by CT, MRI, or ERUS) as an indication of neoadjuvant treatment, Mesorectal $<5 \mathrm{~mm}$ tumor mesorectal growth less than $5 \mathrm{~mm}$, Mesorectal 5-15 mm tumor mesorectal growth 5-15 mm, Distal 1/3 any cancer located in distal 1/3 of the rectum, Distal 2/3 any cancer located in the distal 2/3 of rectum, Poor differentiation any cancer with histological description of poor differentiation, Pathology report pathology report always describes the circumferential resection margin measured in mm, IORT intraoperative radiation therapy available, SSS initial imaging sphincter-saving surgery decided upon initial imaging, New regimen liver met new regime of neoadjuvant treatment if synchronous rectal cancer and liver metastases, One-stage surgery one-stage surgery if resectable rectal cancer and liver metastasis, APR rate $<10 \%$ institutional abdominoperineal resection rate less than 10\%; IRR $>50 \%$ institutional irradiation rate greater than $50 \%$ 
The wide variation in indications for neoadjuvant treatment and radiation rates should alert both national and international rectal cancer expert organizations as well as health-care administrators. The individualized treatment plans for rectal cancer patients should reflect the complexity of the disease and not geography or the surgeons' or institutions' preferences and traditions. Establishment of multidisciplinary teams (MDTs) comprising surgeons, oncologists, radiologists, and pathologists can hopefully elevate the decisions regarding the individual rectal cancer patient to a level where documentation and up-to-date knowledge are focused. In our study we have shown that MDTs significantly influence preoperative decisionmaking (Table 6). Interestingly, regular MDT meetings significantly influence decisions on choice of staging modality, neoadjuvant treatment, and several other critical factors in the preoperative planning of rectal cancer treatment. We believe that regular MDT meetings will improve guideline adherence and quality of rectal cancer care, as recently addressed by Taflampas [22]. According to our analysis, department caseload does not have as much influence on preoperative decision-making.

Over- and understaging as well as over- or undertreatment will have an impact on health-care costs, frequency of side effects of CRT, and surgery, including a patient's quality of life and local recurrence and cancer-specific survival. Continuous education of rectal cancer surgeons seems necessary to increase implementation of evidence-based clinical practice. Heath-care authorities should develop quality control systems in order to ensure adherence to national and international recommendations and guidelines. The national and international societies associated with rectal cancer treatment have the challenge of developing such updated evidence-based recommendations.

Disclosures The Norwegian Health Authorities Research fund supported the study financially by paying Augestad's salary.

Open Access This article is distributed under the terms of the Creative Commons Attribution Noncommercial License which permits any noncommercial use, distribution, and reproduction in any medium, provided the original author(s) and source are credited.

\section{Appendix}

The following surgeons participated in the International Rectal Cancer Study Group (IRCSG) (listed alphabetically by last name): Ambrosetti, Patrick MD (University Hospital of Geneva, Geneva, Switzerland). Andujar, Jose MD (West Penn Allegheny Health System, Pittsburgh, PA, USA). Baixuli, Jorge MD, PhD (Division of Colorectal Surgery, Department of General Surgery, Clínica Universidad de Navarra, Navarra, Spain). Balen, Enrique
MD, PhD (Department of Colorectal Surgery, Hospital de Navarra, Pamplona, Spain). Baxter, Nancy MD, PhD (Li Ka Shing Knowledge Institute of St. Michael's Hospital, University of Toronto, Toronto, ON, Canada). Beck, David MD (Ochsner Clinic Foundation, New Orleans, LA, USA). Bemelman, Willem MD (Academic Medical Centre, Amsterdam, Netherlands). Bergamaschi, Robert MD, PhD, FRCS, FASCRS, FACS (Division of Colon \& Rectal Surgery, State University of New York, NY, USA), Billingham, Rick MD (Department of Surgery, University of Washington, Seattle, WA, USA). Birch, Daniel MSc MD, FCRCS, FACS (Royal Alexandra Hospital, University of Alberta, Edmonton, AL, Canada). Bonardi, Renato MD (Universidade Federal Do Parana, Curitiba, Brazil). Bonardi, Marcos MD (University of São Paulo Medical School, São Paulo, Brazil). Bonjer, Jaap MD (Queen Elizabeth II Health Sciences Centre, Dalhousie University, Halifax, NS, Canada). Braga, Marco MD (San Raffaele University, Italy). Buch, Harikesh MS, FRCS, FRCS (T.N. Medical College \& B.Y.L. Nair Hospital, Mumbai, India). Buechler, Markus MD (Department of Surgery, University of Heidelberg, Heidelberg, Germany). Burnstein, Marcus MD (St Michael's Hospital, University of Toronto, Toronto, ON, Canada). Campbell, Kenneth MB ChB, MD(hons) FRCS(Ed) (Ninewells Hospital \& Medical School, Dundee, UK). Caushaj, Philip MD (Temple University Clinical Campus at The Western Pennsylvania Hospital, Pittsburgh, PA, USA). Celebrezze, James MD (Allegheny General Hospital, Pittsburgh, PA, USA). Chang, George MD (The University of Texas, M. D. Anderson Cancer Center, Houston, TX, USA). Cheong, Denis MD (Tan Tock Seng Hospital, Singapore). Cohen, Jeffery MD, FACS, FASCRS (Department of Surgery, University of Connecticut, Storrs, CT, USA). Colak, Tahsin MD (Medical Faculty of Mersin University, Mersin, Turkey). Delaney, Conor MD, PhD (University Hospitals Case Medical Center, Cleveland, OH, USA). Dhoore, Andre MD, $\mathrm{PhD}$ (University Hospitals Gasthuisberg, Leuven, Belgium), Douglas, Philip MD (St. George and Prince of Wales Hospitals, Sydney, Australia). Dozois, Eric MD, PhD (Mayo Clinic, Rochester, MN, USA). Efron, John MD (Mayo Clinic, Scottsdale, AZ, USA), Ellis, Neal MD (Surgery, University of South Alabama, Mobile, AL, USA). Enker, Warren MD (Memorial Sloan-Kettering Cancer Center, New York, NY, USA). Fanelli, Robert D MD, FACS, FASGE (Department of Surgery, University of Massachusetts Medical School, Worchester, MA, USA). Fazio, Victor MB, BS, FRACS, MS (Department of Surgery, Lerner College of Medicine, Case Western Reserve University and Cleveland Clinic Foundation, Cleveland, OH, USA). Fleshman, James MD (Washington University, St Louis, MO, USA), Franklin, Morris MD (Texas Endosurgery Institute and Baylor College of Medicine, 
University of Texas Health Science Center, San Antonio, TX, USA). Fry, Robert MD (Department of Surgery, The University of Pennsylvania School of Medicine, Philadelphia, PA, USA). Garcia-Aguilar, Julio MD, PhD (University of California, San Francisco, CA, USA). GarciaGranero, Eduardo MD, PhD, EBSQ-C (Department of Surgery, Hospital Clinico Universitario, University of Valencia, Valencia, Spain). Habr-Gama, Angelita MD (University of São Paulo School of Medicine, São Paulo, Brazil). Hahnloser, Dieter MD ESBQ Coloproctology (University Hospital, Zurich, Switzerland). Harris, Guy MD (St. Richards Hospital, Chichester, UK). Hasegawa, Hirotoshi MD, FRCS (Keio University School of Medicine, Tokyo, Japan). Holm, Torbjorn MD, PhD (Department of Surgery, Karolinska University Hospital, Stockholm, Sweden). Horgan, Paul PhD, FRCS (Academic Surgery, University of Glasgow, Glasgow, Scotland). Hyman, Neil MD, FACS (College of Medicine, University of Vermont, Burlington, VT, USA). Irwin, Terry MD (Royal Victoria Hospital, Belfast, Northern Ireland). Joh, Yong-Geul (Hansol Hospital, Seoul, South Korea). Jongen, Johannes MD (Park-Klinik, Kiel, Germany). Kaiser, Andreas MD (Keck School of Medicine, University of Southern California, Los Angeles, CA, USA). Kang, SunBum MD (Department of Surgery, Seoul National University Bundang Hospital, Seoul, South Korea). Kariv, Yehuda MD (Tel Aviv Sourasky Medical Center, Tel Aviv, Israel). Kennedy, Robin MB ChB, MS, FRCS (St. Mark's Hospital, London, UK). Kessler, Hermann MD (University of Erlangen-Nurnberg, Nurnberg, Germany). Khan, Mohammad MD (L \& D Hospital, Luton, UK). Kim, SeonHahn, MD (Korea University Anam Hospital, Seoul, South Korea). Krokowicz, Piotr MD, PhD (Department of General and Colorectal Surgery, Poznan University of Medical Sciences, Poznan, Poland). Kwok, Samuel MD (Hong Kong Sanatorium \& Hospital, Hong Kong). Lacy, Antonio MD (Hospital Clinic, University of Barcelona, Barcelona, Spain). Larson, David MD (Mayo Clinic, Rochester, MN, USA), Law, Wai Lun MS, FRCS (Ed.), FACS (Department of Surgery, University of Hong Kong Medical Center, Queen Mary Hospital, Hong Kong). Lee, Ed MD (Albany Medical Center, Albany, NY, USA). Lindsetmo, Rolv-Ole MD, PhD (Department of Surgery, University Hospital North Norway, Troms $\varnothing$, Norway). Lippert, Hans MD (University Hospital of Magdeburg, Magdeburg, Germany), Ludwig, Kirk MD (Duke University Medical Center, Durham, NC, USA), Lynch, Andrew Craig MD (Peter MacCallum Cancer Center, Melbourne, Australia). MacRae, Helen MA, MD, FRCSC (University of Toronto and Mt. Sinai Hospital, Toronto, ON, Canada). Madbouly, Khaled MD, MS, PhD (Department of Surgery, University of Alexandria, Alexandria, Egypt). Maeda, K. MD (Fujita
Health University, Toyoake, Japan). Marderstein, Eric MD, MPH (Department of Surgery, University Hospitals Case Medical Center, Cleveland, OH, USA). Marino, Mario MD (Department of Surgery, University of Torino, Torino, Italy). Marks, John MD (Lankenau Hospital and Institute of Medical Research, Wynnewood, PA, USA). Maurer, Christoph MD FACS FRCS (Department of Surgery, Hospital of Liestal, University of Basel, Liestal, Switzerland). McLeod, Robin MD (University of Toronto, Toronto, ON, Canada). Monson, John MD PhD (University of Hull, Castle Hill Hospital, Hull, UK). Mortensen, Neil MD (The John Radcliffe Hospital, Oxford, UK), Neary, Paul MD (Adelaide and Meath Hospital incorporating the National Children's Hospital, Dublin, Ireland). Newstead, Graham MB BS, FRACS, FRCS(Eng), FACS, FASCRS, Hon FRSM, Hon FACP (Department of Surgery, University of New South Wales, Sydney, Australia). O'Brien, David MD (Legacy Portland Hospitals, Oregon Health \& Science University, Portland, OR, USA). Orangio, Guy MD (Georgia Colon and Rectal Associates, Atlanta, GA, USA). Orkin, Bruce MD (The George Washington University, Washington, DC, USA). Page, Michael MD, FACS, FASCRS (Iowa Clinic, Des Moines, IA, USA). Påhlman, Lars MD, PhD (Department of Surgery, Uppsala University Hospital, Uppsala, Sweden). Panis, Yves MD (Department of Surgery, Assistance Publique des Hopitaux de Paris, Paris, France). Panton, Neely MB, BS, FRCSC, FACS (Division of General Surgery, University of British Columbia, Vancouver, BC, Canada). Pennickx, Freddy $\mathrm{MD}, \mathrm{PhD}$ (University Hospital, University of Leuven, Leuven, Belgium). Phang, Terry MD, MSc, FRCSC, FACS, FASCRS (Department of Surgery, University of British Columbia,Vancouver, BC, Canada). Pinedo Mancilla, George MD (Catholic University School of Medicine, Santiago, Chile). Post, Stefan MD (University Hospital Mannheim, University of Heidelberg, Heidelberg, Germany). Rafferty, Janice MD (University of Cincinnati, Cincinnati, OH, USA). Rajput, Ashwani MD (University of New Mexico, Albuquerque, NM, USA). Reis Neto, Jose Alfredo dos MD, PhD (Department of Surgery, Catholic University of Campinas, Campinas, Brazil). Reynolds, Harry MD (University Hopsitals Case Medical Center, Cleveland, OH, USA). Rivadeneira, David MD (Stony Brook University Hospital Medical Center, Stony Brook, NY, USA). Roselli, Jorge MD (University Hospital, Bogota, Colombia). Rosen, Harald MD, EBSQ Coloproctology (Department of Surgery, St. Vincent Hospital, Department of Surgery, Vienna, Austria). Rossi, Gustavo MD (Division of Colon and Rectal Sugery, Hospital Italiano de Buenos Aires University of Buenos Aires, Buenos Aires, Argentina). Rouanet, Philippe MD, PhD (Chirurgie Oncologique CRLC Val d'Aurelle, Montpellier, France). 
Rullier, Eric MD (Department of Surgery, University Hospital of Bordeaux, Bordeaux, France). Schiedeck, Thomas MD (Department in Surgery, Klinik für Allgemein- und Viszeralchirurgie, Klinikum Ludwigsburg, Ludwigsburg, Germany). Schiessel, Rudolf MD (Danube Hospital/SMZOst, Vienna, Austria). Schlachta, Christopher BSc, MD CM, FRCSC, FACS (Departments of Surgery and Oncology, Schulich School of Medicine and Dentistry, London Health Sciences Centre Univeristy Hospital, London, ON, Canada). Schwenk, Wolfgang MD, PhD (Charité University Medicine Berlin Campus Mitte, Berlin, Germany). Senagore, Anthony MD, MS, MBA, FACS, FASCRS (Department of Surgery, Michigan State University, Spectrum Health Care, Grand Rapids, MI, USA). Seow-Choen, Francis MD (Seow-Choen Colorectal Centre, Mount Elizabeth Medical Centre, Singapore). Sim, Richard MD (Tan Tock Seng Hospital, Singapore). Sing, Wong Kutt MD (Yong Loo Lin School of Medicine, Singapore). Stamos, Michael MD (Department of Surgery, University of California Irvine Medical Center, Orange, CA, USA). Sternberg, Jeffrey MD (San Francisco Surgical Associates, San Francisco, CA, USA). Tuckson, Wayne MD (University of Kentucky, Lexington, KY, USA). Ugolini, Giampaolo MD, PhD (Università di Bologna, Bologna, Italy). Vaccaro, Carlos MD (Hospital Italiano de Buenos Aires, Buenos Aires, Argentina). Vargas, David MD (University of Kentucky, Lexington, KY, USA). Vignali, Andrea MD (Department of Surgery, IRCCS San RaffaeleUniversity Vita e salute, Milan, Italy). Vonen, Barthold MD, PhD (Department of Surgery, University Hospital North Norway, Troms $\varnothing$, Norway). Weiss, Eric MD, FACS, FASCRS, FACG (Colorectal Surgery, Cleveland Clinic Florida, Fort Lauderdale, FL, USA). Wexner, Steven MD, FACS, FRCS, FRCS (Department of Colorectal Surgery, Cleveland Clinic Florida, Weston, FL, USA). Whiteford, Mark MD, FASCRS (Providence Cancer Center, Oregon Health and Science University, Portland, OR, USA). Wibe, Arne MD, PhD (Department of Surgery, St. Olavs Hospital, University of Trondheim, Trondheim, Norway). Williams, Norman MS FRCS FMedSci (Department of Surgery, The Royal London Hospital, Whitechapel, London, UK). Woods, Ron MD (St Vincent's Hospital, Melbourne, Australia), Yamamoto, Takayuki MD, PhD, FACG (Yokkaichi Social Insurance Hospital, Yokkaichi, Japan), Young-Fadok, Tonia MD (Mayo Clinic Arizona, Scottsdale, AZ, USA).

\section{References}

1. Benson AB 3rd, Choti MA, Cohen AM et al (2000) NCCN practice guidelines for colorectal cancer. Oncology (Williston Park) 14(11A):203-212

2. Glimelius B, Oliveira J (2008) Rectal cancer: ESMO clinical recommendations for diagnosis, treatment and follow-up. Ann Oncol 19(Suppl 2):ii31-ii32
3. Nelson H, Petrelli N, Carlin A et al (2001) Guidelines 2000 for colon and rectal cancer surgery. J Natl Cancer Inst 93(8): 583-596

4. Phelip JM, Milan C, Herbert C et al (2004) Evaluation of the management of rectal cancers before and after the consensus conference in France. Eur J Gastroenterol Hepatol 16(10): 1003-1009

5. Tjandra JJ, Kilkenny JW, Buie WD et al (2005) Practice parameters for the management of rectal cancer (revised). Dis Colon Rectum 48(3):411-423

6. Van Cutsem E, Dicato M, Haustermans K et al. (2007) The diagnosis and management of rectal cancer: expert discussion and recommendations derived from the 9th World Congress on Gastrointestinal Cancer, Barcelona, 2007. Ann Oncol 19 Suppl 6:vi1-vi8

7. Engstrom PF, Arnoletti JP, Benson AB 3rd et al (2009) NCCN clinical practice guidelines in oncology: rectal cancer. J Natl Compr Canc Netw 7(8):838-881

8. DCCG (2009) Danish national guidelines for rectal cancer treatment. http://www.kirurgisk-selskab.dk/dks/krc.htm\#top. Accessed 15 Jan 2010

9. Smith AJ, Driman DK, Spithoff K et al (2010) Guideline for optimization of colorectal cancer surgery and pathology. J Surg Oncol 101(1):5-12

10. Association Francaise de Chirurgie (2007) French national guidelines for rectal cancer treatment. Gastroenterol Clin Biol 31: $1 \mathrm{~s} 9-1 \mathrm{~s} 22$

11. Norwegian Gastrointestinal Cancer Group (2007) Kontrollopplegg ved kolorektalcancer (Norwegian guidelines). Available at http:// www.ngicg.no/gronnbok/gronnbok.htm. Accessed 22 Jan 2010

12. Ward JE, Gattellari M, Solomon MJ (2002) Management of patients with colorectal cancer: do Australian surgeons know the scientific evidence? Arch Surg 137(12):1389-1394

13. Slim K, Panis Y, Chipponi J (2004) Half of the current practice of gastrointestinal surgery is against the evidence: a survey of the French Society of Digestive Surgery. J Gastrointest Surg 8(8): 1079-1082

14. Peppas G, Alexiou VG, Falagas ME (2008) Bowel cleansing before bowel surgery: major discordance between evidence and practice. J Gastrointest Surg 12(5):919-920

15. Kehlet H (2008) Fast-track colorectal surgery. Lancet 371(9615): 791-793

16. Borie F, El Nasser M, Herrero A et al (2008) Impact of the French consensus guidelines on the management of colonic and rectal cancer: a population-based study. J Chir (Paris) 145(3): 247-251

17. Cree M, Tonita J, Turner D et al (2009) Comparison of treatment received versus long-standing guidelines for stage III colon and stage II/III rectal cancer patients diagnosed in Alberta, Saskatchewan, and Manitoba in 2004. Clin Colorectal Cancer 8(3): 141-145

18. Romanus D, Weiser MR, Skibber JM et al (2009) Concordance with NCCN Colorectal Cancer Guidelines and ASCO/NCCN Quality Measures: An NCCN Institutional Analysis. J Natl Compr Canc Netw 7(8):895-904

19. Browman GP (2010) Evidence-based clinical practice guideline development: principles, challenges, and accountability to evidence. J Surg Oncol 101(1):1-2

20. Smith N, Brown G (2008) Preoperative staging of rectal cancer. Acta Oncol 47(1):20-31

21. Smith NJ, Barbachano Y, Norman AR et al (2008) Prognostic significance of magnetic resonance imaging-detected extramural vascular invasion in rectal cancer. Br J Surg 95(2):229-236

22. Taflampas P, Christodoulakis M, de Bree E et al. (2010) Preoperative decision making for rectal cancer. Am J Surg. doi: 10.1016/j.amjsurg.2009.09.023 
23. Ignjatovic D, Bergamaschi R (2006) Rectal cancer: from outcomes of care to process of care. Scand J Gastroenterol 41(6): 636-639

24. Cheung WY, Pond GR, Rother M et al (2008) Adherence to surveillance guidelines after curative resection for stage II/III colorectal cancer. Clin Colorectal Cancer 7(3):191-196

25. Daniels IR, Fisher SE, Heald RJ et al (2007) Accurate staging, selective preoperative therapy and optimal surgery improves outcome in rectal cancer: a review of the recent evidence. Colorectal Dis 9(4):290-301

26. MacFarlane JK, Ryall RD, Heald RJ (1993) Mesorectal excision for rectal cancer. Lancet 341(8843):457-460

27. McCarthy M, Datta P, Khachatryan A et al (2008) Would compliance with cancer care standards improve survival for breast, colorectal and lung cancers? J Epidemiol Community Health 62(7):650-654 